\title{
Construindo imaginários e memórias por meio da pintura La Revista de Santos de Juan Manuel Blanes
}

\section{Building Imagery and Memories by Painting La Revista de Santos by Juan Manuel Blanes}

\section{Cyanna Missaglia de Fochesatto}

Universidade do Vale do Rio dos Sinos (Unisinos)

\section{Resumo}

A presente pesquisa busca analisar uma pintura do artista uruguaio Juan Manuel Blanes. A pintura, intitulada La Revista de Santos, elaborada no ano de 1886, refere-se a uma encomenda que visava homenagear o então presidente militar do Uruguai, Máximo Santos. Nesse sentido, entende-se esta pintura como espaço de memória, representação e identidade nacional. Por meio dela tencionou-se representar os feitos de Máximo Santos exaltando não apenas sua imagem enquanto militar, mas, principalmente, seu governo. Não atoa foi retratado entre uma estátua equestre de Artigas, exposto na obra como elemento simbólico do herói da nação. Além dele, o quadro apresenta diversos outros militares da época, configurando um cenário de apoio político positivo para Santos. Contudo, almeja-se compreender a representação, a memória e os elementos simbólicos que foram intencionalmente construídos na tela, bem como o discurso que se pode investigar por meio da análise iconográfica.

Palavras-chave: Representação; Juan Manuel Blanes; Memória; Pintura.

\section{Abstract}

This work aims to analyze a painting by the Uruguayan artist Juan Manuel Blanes. The painting, entitled La Revista de Santos, elaborated in the year 1886, refers to an order that was intended to honor the then military president of Uruguay, Máximo Santos. In this sense, this painting is understood as space of memory, representation and national identity. Through it he intended to represent the achievements of Maximus Santos not only extolling his image as a soldier, but, above all, his government. Noto was portrayed between an equestrian statue of Artigas, exposed in the work as a symbolic element of the hero of the nation. In addition to it, the picture presents several other military of the time, setting up a scenario of positive political support for Santos. However, it aims to understand the representation, memory and symbolic elements that were intentionally built on the screen, as well as the discourse that can be investigated through iconographic analysis.

Keywords: Representation; Juan Manuel Blanes; Memory; Painting. 


\section{Artigos e Ensaios na atualidade: relações praticadas}

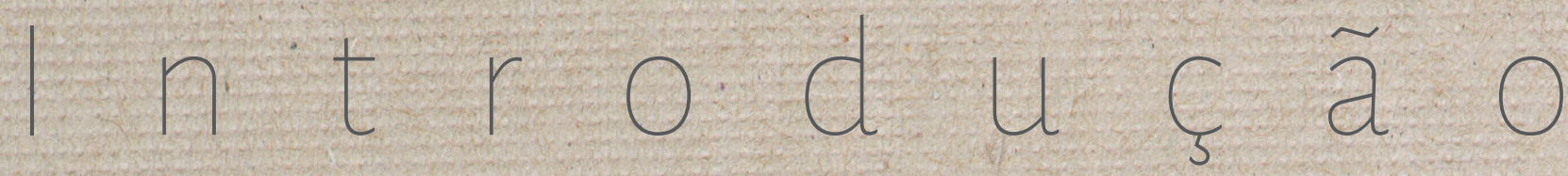

A

pesquisa histórica tem alargado seu campo de investigação nas últimas décadas, partindo da análise de diversos temas e da utilização de fontes de pesquisa alternativas às fontes escritas. Em especial, os avanços nas pesquisas na linha da História Cultural têm apontado um vasto campo investigativo, que por vezes retoma temas já explorados, mas sob a ótica de outras fontes e outras análises. E, nesse caso, as imagens têm contribuído para essa expansão de fontes e objetos de estudo da História. A utilização de pinturas como fonte de pesquisa, embora ainda timidamente venha se tornando objeto de estudo entre os historiadores, vem também se destacando por propiciar a análise partindo dos estudos de representações, memórias, identidades e imaginários. Essas produções, por vezes, são encomendas do Estado ou de determinado grupo, são símbolos nacionais, são imagens que colaboram para contar uma história e fomentar um imaginário social, ou ainda, servem como lugares de memória ${ }^{1}$ de determinada sociedade que busca resgatar lembranças, fatos e acontecimentos que representem uma identidade, uma comunidade ou um grupo social. Tal qual Bronislaw Baczko investiga, seriam símbolos produzidos e representados que ajudam a construir imaginários e, além disso, possuem a função de definir lugares e posições sociais, uma vez que: "O imáginário social, é, pois, uma peça efetiva e eficaz do dispositivo descontrole da vida coletiva e, em especial, do exercício da autoridade e do poder. Ao mesmo tempo, ele torna-se o lugar e o objeto dos conflitos sociais" (BACZKO, 1985, p. 310). A repetição das imagens fomenta um imaginário e também estimula a formação de representações sobre determinados personagens, grupos ou fatos. As imagens são produtoras de sentidos e possuidoras de funções.

Todas as imagens, em todo o caso, têm sua razão de ser, exprimem e comunicam sentidos, são carregadas de valores simbólicos, cumprem funções religiosas, políticas ou ideológicas, prestam-se a usos pedagógicos, litúrgicos e mesmo mágicos. Isso quer dizer que participam plenamente do funcionamento e da reprodução das sociedades presentes e passadas. Em todos os aspectos, elas pertencem ao território de "caça" do historiador (SCHMITT, 2007, p. 11).

1 Entende-se aqui lugares de memória conforme o historiador francês Pierre Nora (1993) que desenvolveu este conceito em seu texto Entre Memória e História: a problemática dos lugares. Nesse caso, acredita-se que a memória não nasce espontaneamente e, porțanto, seria necessário criar. espaços, datas, monumentos, festas, pinturas, comemorações; criar os "lugares de memória" para lembrar ou rememorar aquilo que se tem intenção. 
Jacques Aumont (2000, p. 244), ao trabalhar a relação da imagem e da narrativa histórica, observa que: "A imagem representativa, portanto costuma ser uma imagem narrativa, mesmo que o acontecimento contado seja de pouca amplitude". Sandra Jatahy Pesavento (2008, p. 99) argumenta que: "[...] as imagens são, e têm sido sempre, um tipo de linguagem, ou seja, atestam uma intenção de comunicar", as imagens são simbólicas, portadoras de significados e de signos. Cabe, portanto, aos historiadores problematizarem as fontes que são por eles utilizadas e, no caso das imagens, vinculá-las ao contexto em que foram elaboradas, à biografia do seu autor, a função da imagem na sociedade. Esses são elementos que ajudam a interpretar essas fontes, e são os requisitos fundamentais que favorecem sua análise. Pesavento (2008, p. 18), ainda aborda as imagens da seguinte forma:

As imagens são fruto da ação humana, que interpreta e recria o mundo como representação, exercendo grande fascínio. As imagens são visuais, e carregam consigo esta condição especial que se realiza no plano dos sentidos, ao serem captadas e fixadas por um certo tempo na retina de quem vê. Imagens são, pois, traços de uma experiência sensorial e emotiva.

Contudo, é partindo das três etapas de investigação propostas por Erwin Panofsky que buscamos analisar a pintura La Revista de Santos do artista uruguaio Juan Manuel Blanes. Para Panofsky o método iconológico de análise, que busca fazer um estudo da historicidade da imagem, propõe três etapas de interpretação de uma pintura. A primeira etapa (tema primário ou natural) corresponde à organização e identificação dos motivos artísticos, seria uma espécie de descrição pré-iconográfica da obra. A segunda etapa (tema secundário ou convencional) corresponderia ao momento em que ocorre a associação dos motivos artísticos ao conceito e aos assuntos, ao tema e contexto de produção a imagem. A terceira etapa corresponde à interpretação da obra, revelando seu significado profundo e a compreensão de seu conteúdo, seria a análise do pesquisador (PANOFSKY, 1991, p. 50 - 52). É conforme o método de Panofsky, que se pretende analisar a tela de Blanes neste estudo.

A representação adentra aspectos sociais e políticos, pois é uma estratégia de diferenciação, principalmente entre os distintos grupos, conforme investigaremos ao longo da pesquisa. Para Chartier, ao tratar a representação do mundo social no seu trabalho intitulado O mundo como representação, de 1991, aponta duas vias de interpretação para a representação. A primeira via apresentada por Chartier (1991, p.183) seria a "[...] construção das identidades sociais como resultando sempre de uma relação de força entre as representações impostas pelos que detêm o poder de classificar e de nomear e a definição, de aceitação ou de resistência, que cada comunidade produz de si mesma". A segunda via de representação para Chartier (1991, p. 183), parte da representação que cada grupo forma de si mesmo, seria o reconhecimento de sua existência a partir da demonstração de unidade. 


\section{Artigos e Ensaios Totografia, Arte e História \\ na atualidade: relações praticadas}

Entre outras coisas, essa via "[...] centra a atenção sobre as estratégias simbólicas que determinam posições e relações e que constroem, para cada classe, grupo ou meio, um ser percebido constitutivo de sua identidade". (CHARTER, 1991, p. 183 - 184). Já Eduardo França Paiva (2006, p. 55) considera que: "As representações iconográficas, assim como qualquer outro documento, repito, são lidas sempre no presente, por meio de filtros e chaves, para continuar fazendo uso dessas metáforas, que pertencem ao presente, pelo menos na maioria das vezes".

\section{Juan Manuel Blanes e La Revista de Santos}

Juan Manuel Blanes nasceu no ano de 1830, em Montevideo, e teria elaborado suas primeiras pinturas aos 14 anos de idade. Trabalhou algum tempo como tipógrafo em duas imprensas, mas no ano de 1854 conseguiu abrir seu próprio atelier. No seu atelier passou a se dedicar aos trabalhos encomendados, particularmente aos retratos, principal fonte de renda dos artistas do início do século XIX. Em 1860, Blanes recebeu uma pensão do governo do Estado para aprimorar seus estudos na Europa. No ano seguinte, em 1861, viajou com sua esposa e filhos para Florença, onde aprofundou seus estudos e suas técnicas com o mestre Antonio Ciseri², obtendo uma formação acadêmica - com orientação ao naturalismo. Blanes construiu uma reputação de grande prestígio, sendo reconhecido não apenas na sua terra natal, mas ultrapassando as fronteiras uruguaias (ICLESIAS, 2011, p. 40 - 43). Em 1864, Blanes retorna à Montevideo, sendo também nesse momento que ele inicia seus trabalhos de temas políticos e militares mais relevantes. Acaba regressando para a Europa, em 1879, com a ideia de formar, agora, os seus filhos. Esse artista consagrou-se como "o pintor da pátria" ao representar os temas históricos e as narrativas das batalhas do Uruguai. O pintor veio a falecer em Pisa, no ano de 1901, deixando um apanhando de pinturas que possuem um alto valor histórico e cultural (MANCO, $s / d, s / p)$. Seus trabalhos se configuram como caminhos de uma memória construída por meio de suas pinceladas na tentativa de representar os feitos históricos da sua nação, bem como os tipos sociais que por ela transitaram. Blanes colaborou na construção de imagens de narrativas históricas do Uruguai, dos personagens e das cenas de engrandecimento da nação.

Nesse sentido, Blanes colaborou para a construção de personagens, de heróis, de mitos fundadores que pudessem ajudar a dar uma ideia de unidade, construindo uma noção de identidade

2 Antonio Ciseri (1821-1891) foi um artista suíço que estudou e passou parte de sua vida em Florença, sendo reconhecido especialmente pelas suas pinturas religiosas (de tendências Rafaelitas), além disso, pintou inúmeros retratos ao longo de sua carreira. 
para o Uruguai independente. José Cervasio Artigas foi uma das suas criações mais significativas, foi um personagem construído em dois sentidos, tanto simbolicamente quanto fisicamente ${ }^{3}$. E, na pintura que buscamos aqui analisar, La Revista de Santo ou também conhecida como La Revista de 1885, Artigas aparece como elemento simbólico, embora em forma de estátua equestre, mas também como um sentinela e protetor dos feitos militares que o precederam. Nesse caso, Janice Conçalves (2012, p. 69) afirma que: "complexidade de lugares de memória é destacada em sua riqueza e complexidade são lugares simultaneamente materiais, simbólicos funcionais". Partindo dessa ideia de lugares de memória que Janice Conçalves discute a partir dos estudos de Pierre Nora, podemos pensar a tela aqui analisada (Imagem 1) como um lugar de memória em dois eixos. O primeiro se tratando tela propriamente, uma vez que representa o Presidente Máximo Santos e busca demarcar sua relevấncia no projeto político do Uruguai e, por consequência, seu lugar na memória da sociedade; o outro eixo trata-se de uma representação dentro da tela que traz um monumento à Artigas. Nesse segundo caso, tenciona-se representar uma dupla memória a do passado heroico de Artigas, símbolo construído da Independência do Uruguai, onde sua estátua, tál qual Máximo Santos, possui um lugar de memória. Um lugar de memória e na memória da sociedade Uruguaia representada duplamente na tela pelas figuras de Artigas e Santos.

La Revista de Santos foi concluída em 26 de fevereiro de 1886, depois de um árduo trabalho que perdurou 187 dias, conforme declarou o próprio artista (CARAÑO, MONTERO\& PACANO, 1941, $\mathrm{s} / \mathrm{p}$ ). Essa pintura teria sido encomendada por um grupo de militares e civis que buscavam através do quadro prestar uma homenagem ao Presidente da época, o General Máximo Santos. As$\mathrm{sim}$, foi feita sob encomenda e com o intuito de prestigiar e homenagear um personagem de relevância política e social. Compreende-se que o quadro foi elaborado tendo por fim o enaltecimento da figura do general e seus parceiros políticos e militares, resultando no enaltecimento do governo ditatorial de Máximo Santos.

O General Máximo Santos ficou conhecido pelo seu governo militarista (1880-1886) e também por fazer alianças entre o Exército e o Partido Colorado, conseguindo firmar uma relativa estabilidade política e ordem institucional. Foi um governo de significativo grau de repressão (ALVAREZ, 2006). A obra foi concluída no último ano da ditadura de Santos, logo em seguida ele seria substituído pelo General Máximo Tajes (1886-1890). Máximo Santos foi presidente do Uruguai no período militar por duas vezes, veio a falecer no ano de 1889, três anos após a pintura de Blanes ser executada e exposta ao público. Nas linhas que seguem podemos observar a

3 Blanes não possuía nenhuma imagem recente da aparência de Artigas, apenas uma foto do tempo da mocidade. Assim, teve que construir um corpo e uma face para este personagem. Além disso, a construção de Artigas passou por silenciamento quanto aos seus projetos políticos, uma vez que ele não possuía interesse em um Uruguai independente, mas acabou por tornar-se o símbolo do herói da pátria, o mito fundador de um Uruguai que buscava legitimar sua história nacional partindo do projeto político que exaltava suas batalhas de independência. 


\section{Artigos e Ensaios Totografia, Arte e História na atualidade: relações praticadas}

pintura La Revista de Santos e a forma que o presidente foi retratado. Atentando, inicialmente, para a aura mítica e heroica que esta tela buscou transmitir.

Imagem 1: La Revista de Santos (1886)

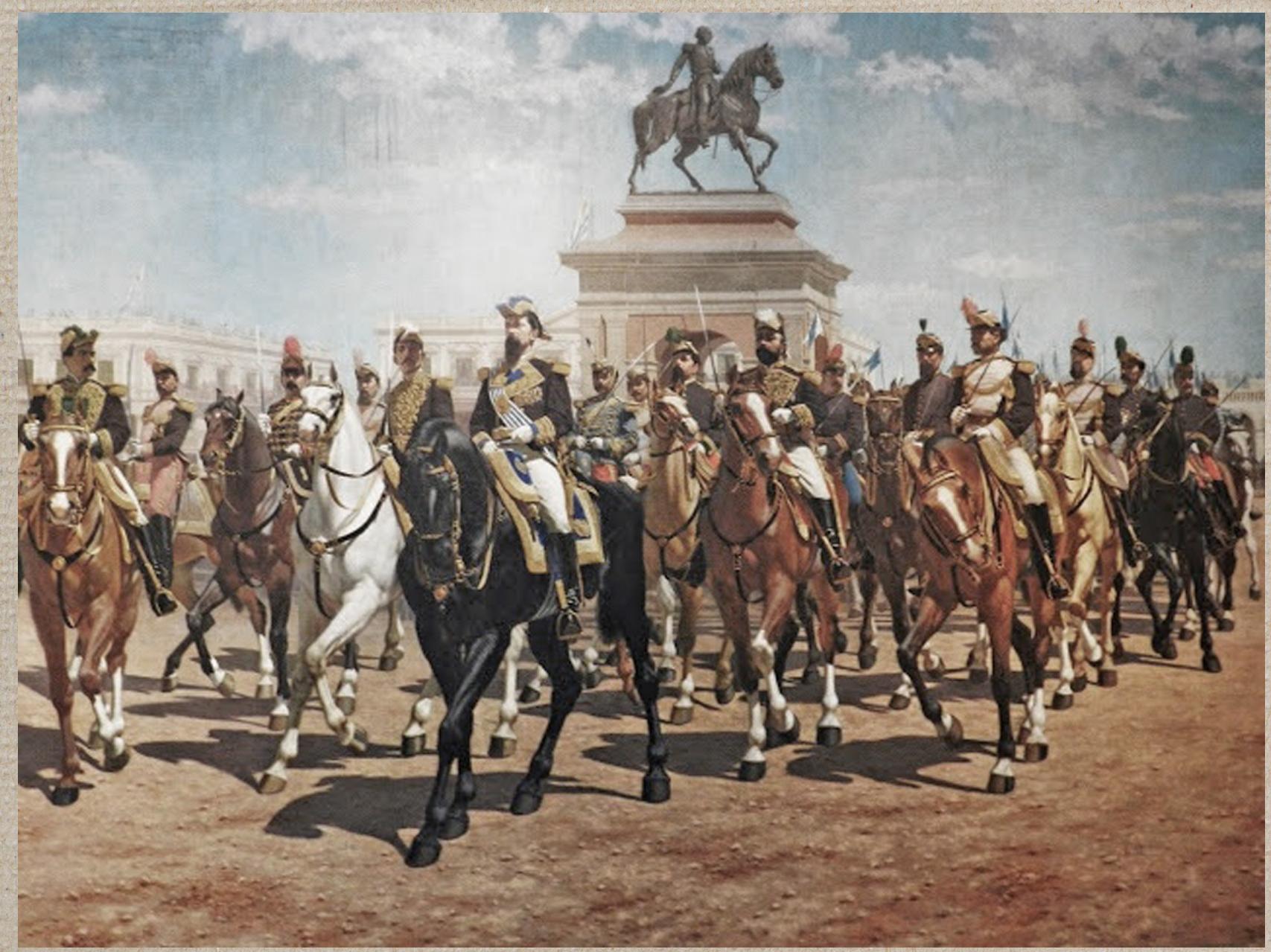

Fonte: (BLANES, 1886)

Esta cena foi retratada na Praça da Independência, localizada no Uruguai, e conta com uma estátua equestre de Artigas ao fundo e, embora essa estátua não existisse na época da execução desta pintura, algumas décadas mais tarde seria elaborada uma estátua de Artigas neste mesmo local. ${ }^{4}$ Essa tela, que foi exposta no Teatro Solis, destaca-se por ser de grandes proporções. Foi parte da decoração da sede da presidência da República, mas, com a queda do regime

4 Segue abaixo a seguinte informação sobra a possibilidade de construir na mesma praça em que está representada a cena da pintura La Revista de Santos uma estátua em homenagem a Artigas. Onde, aproximadamente quarenta anos depois a estátua teria sido erguida no mesmo local em que foi representada por Blanes: "Desde 1882, durante o governo de Máximo Santos, havia uma lei que aprovava um orçamento para a criação de um monumento a José Artigas, "fundador de nuestra nacionalidad"; a pedra fundamental foi colocada em 25 de agosto de 1884, no entanto, o monumento demorou a se materializar. Juan Zorrilla de San Martín esboçou as ideias gerais em “A Epopeia de Artigas"; em 1913, uma comissão declarou vencedores do concurso de projetos o italiano Angelo Zanelli (1879-1942) e o uruguaio Juan Manuel Ferrari (este terminou por ser dispensado). 
militar, a tela foi levada pelos familiares de Santos. Em 1928 a tela foi adquirida pelo município e exposta no MuseoJuan Manuel Blanes, no Uruguai. (LAROCHE, 1963, p. 36).

Nesta representação (Imagem 1) seria possível observar o Ceneral Santos andando a cavalo na praça central guiando outros personagens importantes, como os militares apoiadores de seu governo. O centro da tela apresenta o Ceneral Santos e ao fundo, mais alto e também centralizado, encontra-se a estátua de Artigas. O monumento de Blanes à Artigas chama a atenção por ser uma criação simbólica do pintor, uma vez em que não se tinha tal monumento na praça da Independência. Isso ocorreria também em parte pelo desejo do artista de representar, por meio de signos, os atores principais do processo de construção de um Uruguai independente e próspero (CARAÑO, MONTERO \& PACANO, 1941, s/p). A pintura foi representada em um local simbólico - na praça da Independência - em um dia ensolarado, demarcado através de um céu claro e com algumas nuvens. Portanto, nesta tela são destaques os dois personagens centrais montados a cavalo: Artigas ao fundo, em forma de estátua e o presidente uruguaio Máximo Santos; seria uma alegoria entre o passado e o presente. Pode-se entender que se trata de uma dupla lembrança, a do passado, representado na estátua de Artigas como o herói da nação que lutou pela independência do Uruguai, e do futuro representado naquele momento pelo então presidente Santos. Ainda que seja importante ressaltar que esssas construções memorialísticas são elaboradas em um campo de tensão e conflito e para tanto são necessários diversos mecanismos, em especial, no caso da construção da memória, o esquecimento. Janice Theodoro $(1998$, p. 65$)$ ao estudar a construção da ideia de nação observa que: "Memória e esquecimento são correlatos, datas e marcos são escolhidos para lembrar. Visam formar uma identidade e sentimentos de nação e pertencimento, constroem personagens". E, dessa forma, seria possível pensar o importante papel das imagens na construção de imaginários e memórias: "[...] desestruturação de um imaginário em torno do qual a memória está constituída não pode ser impedida pela existência de um vasto acervo visual, embora as mesmas imagens possam auxiliar a manutenção da memória, quando associada à narrativa" (THEODORO, 1998, p. 61).

Contudo, o que chama a atenção na tela, além das enormes proporções ( $4 \mathrm{mts} \times 6 \mathrm{mts}$ ), são as cores vibrantes e a disposição dos personagens que seguem como sentinelas do presidente. Máximo Santos aparece montado no cavalo, usando suas vestes militares, com a faixa presidencial, onde destacam-se as cores do Uruguai, azul e branco. Possui a cabeça erguida e o olhar fixo para frente, calmamente montado em seu cavalo preto e de pelo brilhante. Em outros pontos da tela nota-se bandeiras do Uruguai erguidas, mais uma vez elementos simbólicos da nação colocados estrategicamente nessa construção pictórica. Outro destaque seriam os detalhes dourados das roupas dos generais militares. Todos eles estão impecáveis com seus uniformes e com os olhos voltados ao presidente Máximo. Seguindo-o sem temer. Parte da tropa está com a espada em punho apontando para o céu. Os cavalos aparecem de diversas cores dando uma perspectiva mais colorida e viva à cena. Sobre as vestes: "Hemos utilizado los reglamentos de uniformes 


\section{Artigos e Ensaios Fotografia, Arte e História \\ na atualidade: relações praticadas}

en vigencia, para describir los uniformes que visten los generales, jefes, oficiales y tropa en el cuadro. Estamos seguros que Blanes utilizó estos reglamentos para el colorido y détalles de los uniformes representados" (PINO, 1992, p. 57). Pode-se dizer que: "El cuadro representa al Presidente de la República [...] montado en su famoso caballo "Pretendiente", a la cabeza del grupo de generales y jefes de las unidades militares del ejército de la época, todos vistiendo uniforme de parada" (PINO, 1992, p. 57). Esses elementos todos são partes constitutivas de uma memória e de uma identidade construída e, nesse caso:

Podemos, portanto, dizer que a memória é um elemento constituinte do sentimento de identidade, tanto individual quanto coletiva, na medida em que ela é também um fator extremamente importante do sentimento de continuidade e de coerência de uma pessoa ou de um grupo em sua reconstrução de si. (POLLAK, 1992, p. 5).

Ainda seria relevante retomar algumas questões sobre a elaboração da estátua de Artigas. Ela aparece ao fundo como para abençoar a cena dos militares. Está acima de todos, montado a cavalo e parece também querer acompanhar a cena seguindo o presidente. Esse elemento colocado por Blanes exemplifica os lugares de memória de Nora. A tela, exposta na sala da presidência, serve como um lembrete constante dos feitos militares de Artigas, para além dos de Máximo Santos, e mostra também um passado glorioso e um futuro promissor. Artigas, contudo, está representando de lado, especialmente para marcar seu lugar fixo na história, ele não acompanha os outros militares, mas está gravado e estruturado na cena. Enraizado na memória onde seu lugar foi constantemente incorporado e rememorado por meio de diversos símbolos e elementos construídos através de ações políticas conscientes.

A memória sendo considerada uma construção política necessita de espaços comemorativos e elementos que demarquem memórias, busca uma identidade por meio da valorização de um passado mesmo que não se tenha vivido esse passado (THEODORO, 1998, p. 69).

Esses elementos simbólicos dão suporte a classe política dominante atestando, entre outras questões, o seu poder. Ressalta-se a importância desses geńerais para a ideia de pátria através de representações cheias de signos dos mesmos. Sobre os sistemas simbólicos, é possível afirmar que: "O poder simbólico é um poder de construção da realidade" (BOURDIEU, 1989, p. 6). Imagens e demais símbolos são representados ao longo da história buscando fabricar memórias, representações e imaginários, forjando identidades e ideias de unicidade identitária a partir da repetição de símbolos e de suas representações. Nesse sentido:

Existe uma luta simbólica entre os diferentes grupos sociais para imporem a visão de mundo mais adequada aos seus interesses. O sistema simbólico reproduz "sob forma irreconhecível, por intermédio da homologia entre o campo da produção ideológica e o campo das classes sociais, a estrutura do campo das classes sociais" (BOURDIEU, 1989. p. 12). 
Abaixo segue uma outra imagem (Imagem 2) com os respectivos personagens representados na pintura La Revista de Santos, apontando mais uma vez que se tratavam de homens e chefes militares de grande importância. O quadro buscou demarcar a relevância deles para a construção de uma representação que além de homenagear o presidente, mostra o suporte e o apoio que o mesmo possui na sociedade, tratando de representá-lo juntamente com outros homens importantes desse momento histórico. O presidente General Máximo Santos seguia guiando sua numerosa comitiva e ao mesmo tempo escoltado e protegido por esses personagens representados como guardiões da nação, vestidos com uniformes militares, empunhados de suas espadas, montados na cavalaria e protegendo o presidente. Tudo isso sob a benção de Artigas, que figura a cima de todos, no centro da tela. Dentre os personagens presentes podemos destacar os seguintes nomes: Ceneral Angel Farías; Tenente Coronel Osvaldo Rodríguez, chefe da $5^{\mathrm{a}}$ cavalaria; Tenente Coronel Pedro de León, chefe da Artilharia; Ceneral da divisão Máximo Tajes, ministro de guerra (será o presidente que assume o governo militar após a saída de Máximo Santos, foi retratado ao lado direito de Santos na pintura); Tenente Coronel Cipriano de Abreu, chefe dos $5^{\circ}$ caçadores (posteriormente também teve um grande retrato seu elaborado por Blanes); entre outros tantos chefes do exércitos e de diversos setores militares presentes na pintura.

Imagem 2: Personagens da tela La Revista de Santos (1.947)

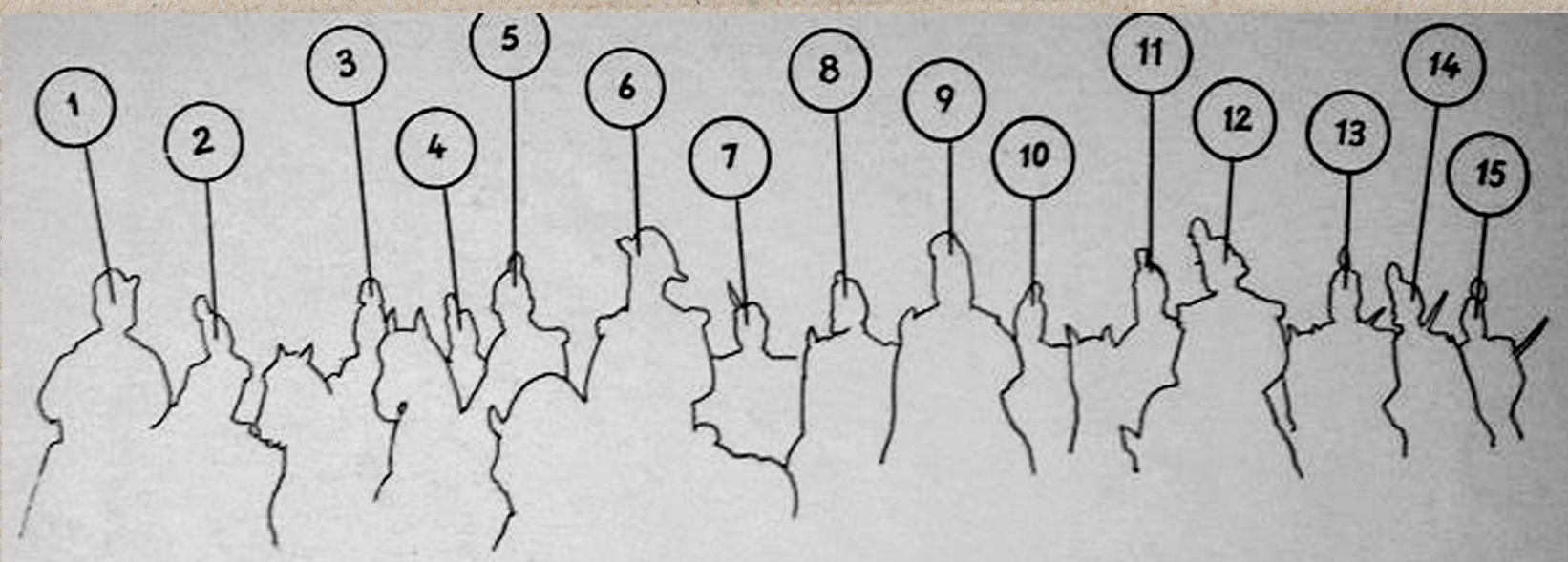

"LA REVISTA DE $1865 "$

(I) General Angel Forías: (2) Teniente Corneel Orraldo Rodrigpez, jefe del 5 de Caballería: (3) Teniente Coronel Pedro de Leća, jefe de La Artillería: (4) Te nimte Coronel Andr's Klisger, jefe del 4." de Caballeria; (5) General de División Márimo Tajex. Miniatro de Guerra: (6) Prenidente de la Repóblica Teaiente General Mírimo Santos; (7) Teniente Comnel Zenín de Teranos jefe de la Fo. colta; (a) Teniente Corociel Salvador Tsjes, jefe del 3.t de Cazadores: (9) General de División Manuel Pagola; (10) Teniente Coronel Antonio Ginori, jefe de Ia Fortaleza del Cerro: (II) Teniente Coronel Cipriano Atirea, jefe del 5 . de Cazadores; (12) Coronel Manuel Benaveate, jefe del 2. de Cazadores: (13) Teniente Coronel José Villar, jefe del 1." de Caballería; (14) Teniente Coronel José Amuedo, jefe del 1." de Cazadores; (I5) Teniente Coronel Josk Gómez, jefe del Cuerpo de Serenoa. 


\section{Artigos e Ensaios na atualidade: relações praticadas}

Essa tela foi estrategicamente composta, assim, Blanes, se utilizou de diversas técnicas e elementos, destacando o uso de fotografia e modelos para compor os personagens representados. Abaixo segue um exemplo das fotografias que Blanes utilizou para a construção da sua tela (Imagem 3). Dessa forma, para além do auxílio da fotografia nas construções pictóricas, podemos perceber o estudo que Blanes fez partindo do suporte de fotografias para conseguir retratar todos os personagens o mais próximo da realidade possível. Utilizou modelos, fotografias, esboços, e por mais de 100 dias teria pintado incansavelmente a tela encomendada.

\section{Imagem 3: Fotografias (s/d)}

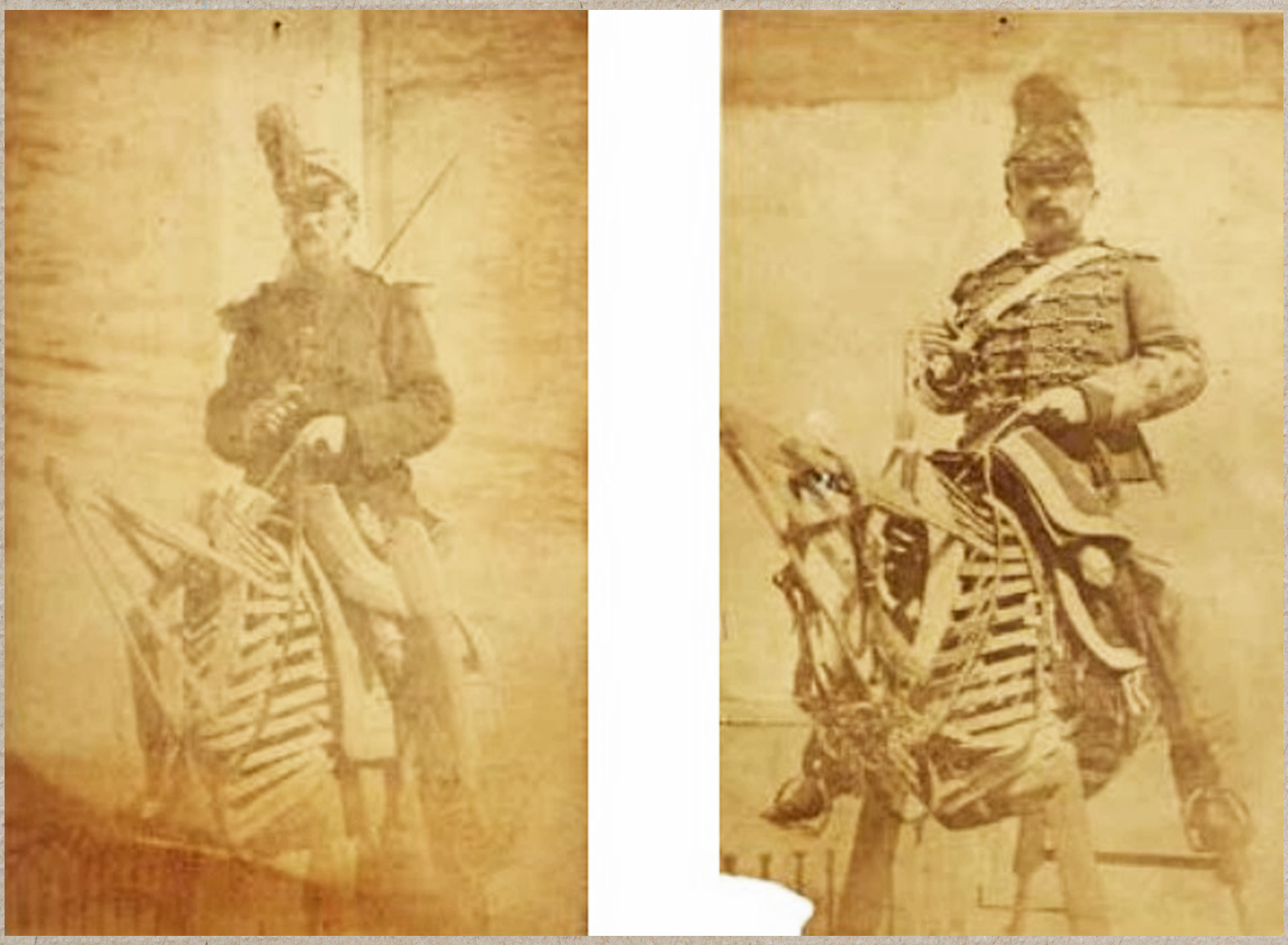

Fonte: (ZORRILLA DE SAN MARTÍN, 2016)

En el cuadro la "Revista de Santos", más conocido como "La Revista de 1885", Juan Manuel Blanes practicó un uso intensivo de la fotografía para la realización de su conocidá obra pictórica. Utilizó este recurso, como un "implemento auxiliar" según anota Valentín Ferdinán, “[...] cuya utilización demuestra una escrupulosidad extrema en la sistematización de los datos a partir de los cuales pintará sus telas" Ofrecemos fotografías de al gunos de los personajes retratados - todos montados en caballete de madera - que utilizó el artista para su tela de grandes dimensiones. Informe reali'zado por el Sr. Alberto Del Pino Menck. (ZORRILLA DE SAN MARTíN, 2016, p.45). 
Sobre a utilização de fotografia na elaboração de pinturas é possível observar uma grande influência em diversos artistas, desde o século XIX, embora seja no século XX que essa influência passa a se tornar mais potente. Sobre a relação da pintura com a fotografia e a influência de uma sobre a outra, observa-se que:

Da mesma forma que o claro e escuro é um recurso visual atribuído ao universo da pintura apropriado pelos fotógrafos - amplamente usado durante o movimento "pictorialista" (1890-1914) - a pintura também absorveu elementos da visualidade e pensamento da imagem fotográfica em seus processos (PELLEGRIN \& COMES, 2011, p. 10).

\section{Considerações finais}

Nas artes, com a emergência de diversas correntes artísticas, também se permitiu um maior desenvolvimento de técnicas, sendo a utilização de fotografias uma das técnicas mais usadas pelos pintores, em especial ao longo do século $X X$. Todos esses elementos foram amplamente utilizados pelas artistas, e colaboraram para a constituição de seus trabalhos e, por consequência, a elaboração simbólica de uma ideia de nação, como no caso da imagem aqui analisada, fazendo parte da construção de um imaginário social a partir de representações pictóricas, sejam elas partindo de estudos, uso de fotografias ou demais elementos. Esse processo de construção de cenas e dos heróis da nação busca também a propagação e manutenção de uma memória, sendo a memória um fenômeno construído, reconstruído e desconstruído, observamos nas palavras de Michael Pollak (1992, p. 4):

As preocupações do momento constituem um elemento de estruturação da memória. Isso é verdade também em relação à memória coletiva, ainda que esta seja bem mais organizada. Todos sabem que a elaboração simbólica de uma ideia de nação, como no caso da imagem aqui analisada, fazendo parte da construção de um imaginário social a partir de representações pictóricas, sejam elas partindo de estudos, uso de fotografias ou demais elementos. Esse processo de construção de cenas e dos heróis da nação busca também a propagação e manutenção de uma memória, sendo a memória um fenômeno construído, reconstruído e desconstruído. 


\section{Artigos e Ensaios na atualidade: relaçôes praticadas}

até as datas oficias são fortemente estruturadas do ponto de vista político. Quando se procura enquadrar a memória nacional por meio de datas oficialmente selecionadas para as festas nacionais, há muitas vezes problemas de luta política. A memória organizadíssima, que é a memória nacional, constitui um objeto de disputa importante, e são comuns os conflitos para determinar que datas e que acontecimentos vão ser gravados na memória de um povo.

Nesse caso, para além dos lugares de memórias e da construção de imaginários, as pinturas também constituem identidades nacionais. A tela La Revista de Santos é construída partindo de diversos elementos simbólicos que destacam de forma positiva o governo ditatorial de Máximo Santos, demostram o apoio que o presidente goza entre seus pares. Passa a ideia de sucesso, ordem e proteção da pátria, já que todos os membros representados no quadro aparecem com seu uniforme militar e empunhando suas espadas. Estão gravados nas telas, em tinta e em memória, os elementos que contribuíram para a construção de narrativas, de memórias e de identidade da sociedade uruguaia. Joel Candau (2013, p.149) traz uma importante reflexão acerca das memórias partilhadas sobre determinados acontecimentos, afirmando que: "[...] uma memória supostamente compartilhada que é selecionada, evocada, invocada e proposta à celebração em um projeto integrador que busca forjar uma unidade: aquela imaginada do acontecimento comemorado e do grupo que o comemora". Nesse sentido, as pinturas são elementos construtores dessa memória forjada que busca trazer uma identidade nacional e a ideia de unicidade da nação. E, nesse caso, Blanes é o arquiteto que constrói, com suas ferramentas seus pincéis e tintas uma memória elaborada a partir de diversos elementos simbólicos e discursos imagéticos gravados em suas telas.

\section{Referências}

ALVAREZ, Maria Ximena. O discurso dos militares para uma "democracia sem conflitos": Uruguai em ditadura e suas fundações discursivas (1973-1985). 2006. Dissertação de Mestrado. 17.3 fls. (Mestrado em História) - Universidade Federal do Paraná, Curitiba. 2006.

AUMONT. Jacques. A imagem. $4^{\text {a ed }}$ Campinas, SP: Papirus, 2000.

BOURDIEU, Pierre. O poder simbólico. Rio de Janeiro: Bertrand Brasil, 1989.

BACZKO, Bronislaw. Imaginação social. In: Enciclopédia Einaudi. s. 1. Lisboa: Imprensa Nacional/Casa da Moeda, Editora Portuguesa, 1985. 
CANDAU, Joël. Antropologia da Memória. Lisboa: Piaget, 2013.

GARAÑO, MONTERO \& PAGANO. Exposiçion Juan Manuel Blanes 1830-1901. Museo Nacional de Bellas Artes. Buenos Aires, 1941.

CHARTIER, Roger. O mundo como representação. Estudos avançados, São Paulo, v. 5, n. 11, p. 173 - 191, 1991.

CONÇALVES, Janice. Pierre Nora e o tempo presente: entre a memória e o patrimônio cultural. In: Revista Historiae, vol. 3, Edição especial. Rio Grande: Editora da FURG, 2012.

IGLESIAS, Eduardo Sellanes. "Juan Manuel Blanes 1830-1901 el pintor de la pátria". 2011. Disponível em: <http://www.onsc.gub.uy/onsc1/images/stories/Publicaciones/RevistaONSC/r46/obras.pdf>. Acesso em: 15 jun. de 2017.

LAROCHE, W. E. Derrotero para una historia del arte en el Uruguay. Montevideo: editora, 1963. v. 3.

MANCO, Elizabethe. "Juan Manuel Blanes, el pintor de la patria". Disponível em: <http://www.uruguayeduca.edu.uy/sites/default/files/2017-05/Juan\%20Manuel\%20Blanes\%2C\%20el\%20Pintor\%20de\%20 la\%20Patria.pdf>.Acesso em: 10 jun. 2016.

NORA, Pierre. Entre Memória e História: a problemática dos lugares. In: Projeto História. São Paulo: PUC, n. 10. dez. 1993, p. 07-28.

PAIVA, Eduardo França. História \& Imagens. 2 ed. Belo Horizonte: Autêntica, 2006.

PANOFSKY, Erwin. Iconografia e Iconologia: uma Introdução ao Estudo do Renascimento. In: PANOFSKY, Erwin. Significado nas Artes Visuais. São Paulo: Perspectiva, 1991.

PELLEGRIN, Ricardo; COMES, Paulo César Ribeiro. Fotografia e pintura: Aspectos da representação na visualidade contemporânea. 2011. Disponível em: <https://periodicos.ufpel.edu.br/ojs2/index.php/Arte/ article/download/15/11>. Acesso em: 11 jul 2017.

PESAVENTO, Sandra ].; SANTOS, Nádia Maria Weber; ROSSINI, Miriam de Souza. Narrativas, imagens e práticas sociais: Percursos em História Cultural. Porto Alegre: Asteriscos, 2008.

PINO, Alberto del. Aportes para el estudio del cuadro de Juan Manuel Blanes "la revista de 1885". 1992. Disponivel em: <http://www.artigas.org.uy/bibliotecas/he/123.\%20Boletin\%20Historico.\%20Nos. $\% 20$ 283\%20-\%20286/Publicacion.pdf>. Acesso em: 9 jul. 2017.

POLLAK, Michael. Memória e identidade social. In: Revista Estudos Históricos. Rio de Janeiro: FCV, vol. 5 , n. 10, 1992.

SCHMITT, Jean-Claude. O corpo das imagens: Ensaio sobre a cultura visual na Idade Média. Bauru-SP: EDUSC, 2007. 
Artigos e Ensaios

Fotografia, Arte e História na atualidade: relaçóes praticadas

THEODORO, Janice. Memória e esquecimento: nos limites da narrativa. In: Revista Tempo Brasileiro, out.I dez. 1998, n 135. Rio de Janeiro: Tempo Brasileiro.

ZORRILLADESANMARTÍN,Sebastián.Plateríacriollaycolonial-militaria-armas-documentosypiezashistóricas.2016.Disponívelem:<http://www.zorrilla.com.uy/imgs/remates/00010/2016_8_3_14_10_4500010. pdf>. Acesso em: 20 de jun. 2017.

130

Resgate-Rev. Interdiscip. Cult., Campinas, v. 26, n. 2 [36], p. 117-130, jul./dez. 2018 -e-ISSN: 2178-3284 